\title{
Ultrafiltration Through Peritoneal Dialysis in Refractory Congestive Heart Failure Patients: One Center Experience
}

\begin{abstract}
Aysegul ORUC (iD), Mehmet Fethullah AYDIN (D), Abdulmecit YILDIZ (iD, Mahmut YAVUZ (D), Mustafa GULlULU (iD, Kamil DILEK ID, Alparslan ERSOY (D)

Division of Nephrology, Department of Internal Medicine, Bursa Uludag University Faculty of Medicine, Bursa, Turkey
\end{abstract}

\begin{abstract}
Background

Hypervolemia is an important consequence of heart failure (HF) that leads poor quality of life and frequent hospitalizations. Ultrafiltration (UF) with dialysis is an option for HF patients who are resistant or inappropriate for diuretics. Peritoneal dialysis (PD) can be a long-term efficient solution for hypervolemia in appropriate $\mathrm{HF}$ patients.
\end{abstract}

\section{Material and Methods}

We retrospectively evaluated $\mathrm{PD}$ patients in our center in order to determine the ones whose indication was UF for volume control because of HF between January 2015 and January 2020.

\section{Results}

4 (2 females, $68.75 \pm 4.27$ years old) HF patients who had poor volume control on diuretic based regimen were on PD for UF. PD treatment was planned as a daily single exchange with icodextrin in whom all had preserved renal function. In one patient one daily exchange with an amino acid-based PD solution was added. Exchange volume was between 1000 and $1500 \mathrm{~mL}$, dwell time was 9 to 14 hours and UF was 200 to $1100 \mathrm{~mL}$. During the follow-up patients lost adequate weight and none of them were hospitalized because of hypervolemia.

\section{Conclusions}

UF through PD in HF patients provides effective volume control, relief of symptoms and avoids frequent hospitalizations. A single daily exchange with icodextrin can be adequate for hypervolemic, well selected HF patients.

Turk J Int Med 2020;2(4):118-122

DOI: $\underline{10.46310 / \text { tjim.768289 }}$

Keywords: ultrafiltration, peritoneal dialysis, refractory congestive heart failure 


\section{Introduction}

Heart failure (HF) is a clinical syndrome characterized by typical symptoms that may be accompanied by signs caused by a structural and/or functional cardiac abnormality, resulting in a reduced cardiac output and/or elevated intracardiac pressures at rest or during stress. ${ }^{1}$ Hypervolemia is an important consequence of $\mathrm{HF}$ that leads poor quality of life and frequent hospitalizations. Furthermore, infection, electrolyte imbalances, and deterioration in renal function usually accompany frequent hospitalizations which are associated with morbidity and mortality risk. Salt restriction and diuretics are major components of lifestyle changings and diuretic based medical therapy for hypervolemia, respectively. In addition, ultrafiltration (UF) with dialysis is an option for $\mathrm{HF}$ patients who are resistant or inappropriate for diuretics. Additionally, there is a bidirectional association between renal and cardiac functions which is defined as cardiorenal syndrome. Due to this relationship, dialysis may be required in some cases beyond UF. ${ }^{2}$

In the cardiology guidelines, UF is recommended to be considered only for patients with refractory congestion, who failed to respond to diuretic based medical therapies. ${ }^{1,3}$ On the other hand, in practice $\mathrm{UF}$ is performed more frequently for hypervolemia in congestive HF patients. UF procedure is the removal of the water and small to medium weight solutes across a semipermeable membrane with hemodialysis (HD) and peritoneal dialysis (PD). UF has several advantages in the HF patients of allowing reuse of an angiotensin converting enzyme inhibitors (ACEI) or angiotensin receptor blockers (ARB) or aldosterone antagonist which are associated with improved survival. Secondly, reducing diuretic doses prevents renal dysfunction and electrolyte imbalances. Nevertheless, compared with diuretic based treatment survival advantage of UF procedures are controversial. ${ }^{2}$

$\mathrm{PD}$ has been used for UF in the HF patients almost for 60 years. ${ }^{4} \mathrm{UF}$ through PD has some superiority compared with HD which are decreasing frequency of hospitalization, improvement in quality of life, decreasing in diuretic dose, comfort of home therapy, preserving residual renal function and hemodynamic stabilization. In all, the most important is slow removal of excess water which avoids hypotension in $\mathrm{HF}$ patients who are mostly vulnerable to unstable hemodynamics. ${ }^{2}$ With these regards' PD seems to be a promising option for patients who are resistant to medical treatments and/or require frequent hospitalization

We aimed to present our experience of PD for UF in patients with HF who requires frequent hospitalization for volume control.

\section{Material and Methods}

We retrospectively evaluated $\mathrm{PD}$ patients in our center in order to determine the ones whose indication was UF for volume control because of HF between January 2015 and January 2020. The data was obtained from electronic files. Demographic and laboratory data, hospitalizations for volume control, medical complications, and medications were recorded. At our center PD is considered for UF in diuretic resistant, frequently hospitalized (more than 4 in a year), accompanying renal dysfunction, and hypervolemic HF patients.

\section{Statistical Analysis}

Statistical analyses were performed with SPSS software (SPSS: An IBM Company, version 23.0, IBM Corporation, Armonk, NY, USA). The numerical and categorical variables were expressed as the mean \pm standard deviation and ratios, respectively.

\section{Results}

$76 \mathrm{PD}$ patients (50\% female, $53.43 \pm 15.54$ years old) were retrospectively evaluated. PD modality was continuous ambulatory peritoneal dialysis (CAPD) in 36 (47.4\%), automated peritoneal dialysis (APD) in $36(47.4 \%)$ patients. In 4 (68.75 \pm 4.27 years old) patients who were diagnosed $\mathrm{HF}, \mathrm{PD}$ was initiated for UF. Main reason of PD initiation was poor volume control and frequent hospitalization. 2 of $4 \mathrm{HF}$ patients were female. All of 4 had poor volume control on diuretic based regimen with physical examination of tense ascites, pretibial pitting edema, and pulmonary rales. Laboratory findings revealed mean 
urea of $101 \pm 42.43 \mathrm{mg} / \mathrm{dL}$, serum creatinine of $2 \pm 0.47 \mathrm{mg} / \mathrm{dL}$, eGFR of $36.75 \pm 13.84 \mathrm{~mL} / \mathrm{min}$, serum sodium $(\mathrm{Na})$ of $133 \pm 5.2 \mathrm{mmol} / \mathrm{L}$, serum albumin of $3.4 \pm 0.3 \mathrm{~g} / \mathrm{dL}$ and hemoglobin of $10.47 \pm 1.33 \mathrm{~g} / \mathrm{dL}$. All HF patients had diuresis with a mean daily volume of $1100 \mathrm{~mL}$ under furosemide. A PD catheter was implanted by interventional radiologist under local anesthesia for all. PD treatment was planned as a daily single exchange with icodextrin in whom all had preserved renal function. In one patient one daily exchange with an amino acid-based peritoneal dialysis solution was added because of low serum albumin levels due to malnutrition. Exchange volume was between 1000 and $1500 \mathrm{~mL}$, dwell time was 9 to 14 hours and UF was 200 to 1100 $\mathrm{mL}$. During the follow-up, patients lost adequate weight and none of them were hospitalized because of hypervolemia. Peritonitis was occurred in 2 of 4 patients. 1 patient died because of sepsis due to uncontrolled peritonitis though peritoneal catheter was removed. It was learned that he went to toilet while PD exchange, and Candida albicans and Acinetobacter baumannii were isolated in the dialysate solution. A female one had poor family support for that reason they failed to perform proper PD program. Consequently, she passed away after 10 months of PD initiation due to cardiovascular reasons. 1 patient died after the mitral valve surgery because of cardiac reasons at the $8^{\text {th }}$ month of PD treatment.

The $4^{\text {th }}$ one is still on the PD program for 16 months who is free of peritonitis, ascites and pretibial edema. He did not require hospitalizing through this interval. His PD schedule is consisting of a 12-hour $1500 \mathrm{~mL}$ icodextrin and an 8-hour $1500 \mathrm{~mL}$ amino acid-based solution exchanges on alternate days with $900 \mathrm{~mL}$ and $100 \mathrm{~mL}$ daily UF, respectively.

\section{Discussion}

Traditionally HF treatment has 2 components of lifestyle changes and medical treatment. The lifestyle changings are salt and fluid restriction, smoking cessation and weight control. The medical treatments are consisting diuretics, ACEI or ARB, vasodilators and beta blockers. In additionally some advanced cases require more aggressive approaches such as cardiac devices, pacemakers, and mechanical circulatory support. The association between cardiac and renal functions may lead to obstacles for using ACEI/ARB, and/or diuretics. Furthermore, unresponsiveness to diuretics or inadequate dosage due to adverse outcomes of diuretics like renal function deterioration, electrolyte imbalance can provoke worsening volume control. For patients with volume overload refractory to diuretics UF can be considered through HD or PD.

In the EUPHORIA study peripheral venovenous UF was significantly decreased length of hospital stays and readmissions in $20 \mathrm{HF}$ patients with volume overload and diuretic resistance. ${ }^{5}$ In the UNLOAD study UF strategy were stated safe and superior to diuretics in respect of volume control and rehospitalization among 200 decompensated HF patients. However, dyspnea scores, renal functions and mortality were similar among the groups. ${ }^{6}$ Opposite to these findings in the CARRESS-HF study, UF was found inferior to a stepped pharmacologic-therapy algorithm for the preservation of renal function at 96 hours and associated with a higher rate of adverse events. Also, weight loss was similar with the two approaches. ${ }^{7}$

UF by $\mathrm{PD}$ is thought of being more advantageous compared with extracorporeal circuits. Slow removal of fluid by PD provide adequate time for allowing vascular refilling from extravascular spaces thereby avoiding hypotension in hemodynamically instable $\mathrm{HF}$ patients. Additionally, PD is performed at home that provides comfort for patients and improves quality of life. PD regimens for UF differ from usual dialysis $\mathrm{PD}$ regimens in exchange frequency. ${ }^{2}$ Fewer exchanges can provide adequate UF with icodextrin. ${ }^{8}$ A single daily icodextrin exchange offers better quality of life, freedom of movement, economic benefit with efficient fluid removal. Moreover, as already known PD preserves residual renal function better than HD. ${ }^{9}$

In our center we initiated PD for UF in $4 \mathrm{HF}$ patients who had volume control problem under diuretic consisting medical treatment and required frequent hospitalizations. During the follow-ups none of the patients were hospitalized because of hypervolemia. Due the purpose of PD initiation all the patients were free of hospitalization. We did not investigate the quality of life by an item but in our outpatient clinic visits the patients and their families stated us the pleasure of being away 
from hospitals. The pleasure is also a consequence of staying at home during PD. Compatible with the literature we planned the PD regimen as a single daily exchange with icodextrin. The dwell time was modified according to UF performance of changing between 9 to 14 hours. Because they did not require dialysis this program was adequate for volume control.

Intravenous diuretics provoke sympathetic nervous, renin angiotensin aldosterone, endothelin and vasopressin systems which are associated with mortality. ${ }^{10}$ This neurohumoral activation do not occur with PD due to slow volume removal. Furthermore, preservation of residual renal function is an advantage of PD compared with diuretics in HF patients. ${ }^{11}$ As we nephrologist know the value of every drop of urine, we effort hard to preserve residual renal function. All our HF patients had already have diuresis and during the efficient fluid removal through PD their urine volume did not decrease.

PD catheter insertion under local anesthesia should be preferred because of general anesthesia risks in HF patients. Immediate initiation also can be possible compared with laparoscopic insertion. ${ }^{2}$ We also preferred to insert the PD catheter under local anesthesia. After the interventional radiologist implanted the catheter there were no problem associated with the catheter and we began the exchanges after approximately 3 days after implantation.

Patient selection criteria for PD essential because the success of PD mostly depends on care giver. Mental function, strength, learning skills, and ability of performing PD practice properly are the main factors for success associated with the care giver or the patient. One of our patients had visual problems and peripheral polyneuropathy due to diabetes mellitus and her daughter was educated for PD according to the family decision. But throughout the process the daughter had unwillingness of care of her mother. Even the patient's regular visits were disrupted. As a consequence, the patient died due to cardiac reasons at another center. We suggest that the clinician has to be sure about the willingness, family support, and strength of the patient and/or the caregiver before the PD decision.

Peritonitis is an important complication of PD and in the studies, it is the most reported complication associated with PD in HF patients.
The rates ranged from 0.02 to 0.46 episodes which is similar to peritonitis rates among end stage renal disease PD patient. ${ }^{12}$ In our center peritonitis rate was $0.5 /$ patient year which is proper according to guidelines. The ISPD guidelines recommended that peritonitis rate should not be more than 0.5/ patient year..$^{13} 2$ of our patients has peritonitis episodes and in 1 patient the peritonitis caused catheter removal and death.

Mortality rate among HF patients is high. In the studies with follow-up period $\geq 1$ year the overall mortality was $48.3 \%$ in HF patients underwent PD for UF. ${ }^{12}$ Different of that argument in some studies that had follow-up time $\leq 1$-year remarkable survival rates of $85 \%$ were reported. ${ }^{13}$ In a systemic review of PD in HF patients it is stated that there are no differences in mortality between PD and extracorporeal circuits. ${ }^{14} 1$ of 4 patients was survived in our group for 16 months. Whereas only 1 patient died because of PD related complications. As a result, mortality risk is high in advanced HF patients and survival advantage of $\mathrm{PD}$ is controversial.

In conclusion $\mathrm{PD}$ is an advantageous option for UF in HF patients that provides effective volume control, relief of symptoms and avoids frequent hospitalizations. A single daily exchange with icodextrin can be advisable for hypervolemic, well selected HF patients.

\section{Conflict of interest}

The authors declared that there are no potential conflicts of interest with respect to the research, authorship, and/or publication of this article.

\section{References}

1. Ponikowski P, Voors AA, Anker SD, Bueno H, Cleland JGF, Coats AJS, Falk V, González-Juanatey JR, Harjola VP, Jankowska EA, Jessup M, Linde C, Nihoyannopoulos P, Parissis JT, Pieske B, Riley JP, Rosano GMC, Ruilope LM, Ruschitzka F, Rutten FH, van der Meer P; ESC Scientific Document Group. 2016 ESC Guidelines for the diagnosis and treatment of acute and chronic heart failure: The Task Force for the diagnosis and treatment of acute and chronic heart failure of the European Society of Cardiology (ESC) Developed with the special contribution of the Heart Failure Association (HFA) of the ESC. Eur Heart J. 2016 Jul 14;37(27):2129-200. doi: 10.1093/eurheartj/ehw128.

2. Puttagunta H, Holt SG. Peritoneal Dialysis for Heart 
Failure. Perit Dial Int. 2015 Nov;35(6):645-9. doi: 10.3747/ pdi.2014.00340.

3. Hollenberg SM, Warner Stevenson L, Ahmad T, Amin VJ, Bozkurt B, Butler J, Davis LL, Drazner MH, Kirkpatrick JN, Peterson PN, Reed BN, Roy CL, Storrow AB. 2019 ACC Expert Consensus Decision Pathway on Risk Assessment, Management, and Clinical Trajectory of Patients Hospitalized With Heart Failure: A Report of the American College of Cardiology Solution Set Oversight Committee. J Am Coll Cardiol. 2019 Oct 15;74(15):19662011. doi: 10.1016/j.jacc.2019.08.001.

4. Schneierson SJ. Continuous peritoneal irrigation in the treatment of intractable edema of cardiac origin. Am J Med Sci. 1949 Jul;218(1):76-9. doi: 10.1097/00000441194907000-00011.

5. Costanzo MR, Saltzberg M, O'Sullivan J, Sobotka P. Early ultrafiltration in patients with decompensated heart failure and diuretic resistance. J Am Coll Cardiol. 2005 Dec 6;46(11):2047-51. doi: 10.1016/j.jacc.2005.05.099.

6. Costanzo MR, Guglin ME, Saltzberg MT, Jessup ML, Bart BA, Teerlink JR, Jaski BE, Fang JC, Feller ED, Haas GJ, Anderson AS, Schollmeyer MP, Sobotka PA; UNLOAD Trial Investigators. Ultrafiltration versus intravenous diuretics for patients hospitalized for acute decompensated heart failure. J Am Coll Cardiol. 2007 Feb 13;49(6):675-83. doi: 10.1016/j.jacc.2006.07.073.

7. Bart BA, Goldsmith SR, Lee KL, Givertz MM, O'Connor CM, Bull DA, Redfield MM, Deswal A, Rouleau JL, LeWinter MM, Ofili EO, Stevenson LW, Semigran MJ, Felker GM, Chen HH, Hernandez AF, Anstrom KJ, McNulty SE, Velazquez EJ, Ibarra JC, Mascette AM, Braunwald E; Heart Failure Clinical Research Network. Ultrafiltration in decompensated heart failure with cardiorenal syndrome. N Engl J Med. 2012 Dec
13;367(24):2296-304. doi: 10.1056/NEJMoa1210357.

8. Basile C, Chimienti D, Bruno A, Cocola S, Libutti P, Teutonico A, Cazzato F. Efficacy of peritoneal dialysis with icodextrin in the long-term treatment of refractory congestive heart failure. Perit Dial Int. 2009 JanFeb;29(1):116-8.

9. Selby NM, Kazmi I. Peritoneal dialysis has optimal intradialytic hemodynamics and preserves residual renal function: Why isn't it better than hemodialysis? Semin Dial. 2019 Jan;32(1):3-8. doi: 10.1111/sdi.12752.

10. Ellison DH. Diuretic therapy and resistance in congestive heart failure. Cardiology. 2001;96(3-4):132-43. doi: 10.1159/000047397.

11. Nakayama $M$, Nakano $H$, Nakayama $M$. Novel therapeutic option for refractory heart failure in elderly patients with chronic kidney disease by incremental peritoneal dialysis. J Cardiol. 2010 Jan;55(1):49-54. doi: 10.1016/j.jjcc.2009.08.003.

12. Chionh CY, Clementi A, Poh CB, Finkelstein FO, Cruz DN. The use of peritoneal dialysis in heart failure: A systematic review. Perit Dial Int. 2020 Jan 13:896860819895198. doi: 10.1177/0896860819895198.

13. Li PK, Szeto CC, Piraino B, de Arteaga J, Fan S, Figueiredo AE, Fish DN, Goffin E, Kim YL, Salzer W, Struijk DG, Teitelbaum I, Johnson DW. ISPD Peritonitis Recommendations: 2016 Update on Prevention and Treatment. Perit Dial Int. 2016 Sep 10;36(5):481-508. doi: 10.3747/pdi.2016.00078.

14. Bertoli SV, Musetti C, Ciurlino D, Basile C, Galli E, Gambaro G, Iadarola G, Guastoni C, Carlini A, Fasciolo F, Borzumati M, Gallieni M, Stefania F. Peritoneal ultrafiltration in refractory heart failure: a cohort study. Perit Dial Int. 2014 Jan-Feb;34(1):64-70. doi: 10.3747/ pdi.2012.00290. 